\title{
Lack of Evidence for Impact of the European White Birch, Betula pendula, on the Hydrology of Wainfleet Bog, Ontario
}

\author{
Joshua Diamond ${ }^{1}$, Mark Browning ${ }^{2}$, Andrew Williams $^{3}$, and John MidDleton ${ }^{4}$ \\ ${ }^{1}$ Niagara Peninsula Conservation Authority, Welland, Ontario L3C 3W2 Canada \\ ${ }^{2}$ Ontario Ministry of Natural Resources, Wildlife Research and Development Section, Peterborough, Ontario K9J 8M5 Canada \\ ${ }^{3}$ School of Mathematics and Statistics, Carleton University, Ottawa, Ontario K1S 5B6 Canada \\ ${ }^{4}$ Centre for the Environment, Brock University, St. Catharines, Ontario L2S 3A1 Canada
}

Diamond, Joshua, Mark Browning, Andrew Williams, and John Middleton. 2004. Lack of evidence for impact of the European White Birch, Betula pendula, on the hydrology of Wainfleet Bog, Ontario. Canadian Field-Naturalist 117(3): 393-398.

Over time peat harvesting and human encroachment have devastated the hydrology of Wainfleet Bog. Disturbances caused by human activities have rendered the bog ecosystem vulnerable to an influx of invasive species. The European White Birch (Betula pendula) has contributed to the degradation of the Wainfleet Bog. The disrupted hydrology has allowed for the development of dry conditions that have enabled $B$. pendula to take over habitats that were once dominated by native flora. To determine whether $B$. pendula was depressing the water table through evapotranspiration, we examined water table levels (March 1998 to July 1999) and vegetative data from 15 well stations. Analysis of results using a Repeated Measures Statistic Design failed to demonstrate a significant relationship between the presence of B. pendula and water table levels at Wainfleet Bog.

Key Words: Betula pendula, Wainfleet Bog, Ontario, birch, invasive species, hydrology, bog.

This study was designed to investigate the effects of the European White Birch (Betula pendula) on the hydrology of Wainfleet Bog. Wainfleet Bog is the largest wetland in the Niagara Region and its ecological value is significant. More than $80 \%$ of the wetlands in the Niagara Region have been converted to other land uses (Environment Canada 1986). Wainfleet Bog has not been spared human intervention. Over the last century more than one third of this bog has been lost to peat extraction and agricultural activities. However, this ecosystem still supports a variety of provincially rare species such as the Massasauga Rattlesnake (Sistrurus catenatus catenatus) (Niagara Peninsula Conservation Authority 1997). Most of the bog is now publicly owned and managed by the Niagara Peninsula Conservation Authority (NPCA), the Ontario Ministry of Natural Resources (MNR), and the Nature Conservancy of Canada (NCC). The shared goal of these agencies is to restore the Wainfleet Bog ecosystem to a healthy, less-disturbed state, providing recreational, educational and scientific opportunities for existing and future generations.

The disruption of the hydrology of Wainfleet Bog has been identified as the primary barrier to rehabilitating this ecosystem. The harvesting of peat severely impacted sections of the bog as the construction of drainage ditches and channels lowered the water table. According to Clymos and Hayward (1982), decreases to water table levels are catastrophic to Sphagnum spp. populations as they are unable to survive in these drier conditions and perish due to desiccation. In addition, the harvesting of peat changes the chemical composition (Wind-Mulder et al. 1996) of the bog, and removal of the viable seed bank through direct harvesting impairs the natural regeneration of bogs (Salonen 1987). All of these factors have created ideal conditions for $B$. pendula to invade this ecosystem.

Betula pendula is regarded as one of the five invasive plants that will have a major impact on the ecosystems of Canada (Environment Canada 1997). B. pendula is well described as a pioneer species in disturbed ecosystems in Spain (Reyes et al. 1997). The seeds of $B$. pendula are wind dispersed and have been reported to disperse between hundreds and thousands of metres (Reyes et al. 1997). Seeds usually prefer sunny places free from plant cover to germinate (Atkinson 1992). Areas which have been harvested for peat, or have been burned are ideal for establishment. Houle (1991) found the seeds of $B$. pendula form a persistent seed bank with a very high rate of renewal. Reyes et al. (1997) found $B$. pendula to grow quickly and reach a great height within a short time. Lavoie and Saint-Louis (1999) reported Betula populifolia, a pioneer species with similar ecological requirements to $B$. pendula, spreading throughout abandoned peatlands in eastern Quebec.

Betula pendula is naturally distributed throughout most of Asia and Europe, from Sicily to the $69^{\circ} \mathrm{N}$ in Norway (Atkinson 1992). However, it has been cultivated for many years in Canada by nurseries as an ornamental tree. Peat harvesting and decreases in water table level have allowed the invasion of $B$. pendula into the Wainfleet Bog ecosystem (Catling and Spicer 1988; Jonsson-Ninniss and Middleton 1991; MacDonald 1992). B. pendula is currently thriving in the present conditions found in this bog. Impenetrable forests of $B$. pendula dominate much of the landscape within Wainfleet Bog and cover an area of several hundred hectares. 
The presence of B. pendula has been identified as a partial cause for the failure of the reestablishment of the Wainfleet bog hydrology. Lavoie and SaintLouis (1999) suggested that massive invasions by birch trees into abandoned peatlands may have a detrimental effect on the water table. Schouwenaars (1988) also reported that evapotranspiration by trees and bushes impacts the water table level of disturbed bog relicts in the Netherlands. Furthermore, Kozlowski and Pallardy (1997) show that species in the genus Betula generally have a much higher transpiration rate than oak (Quercus), beech (Fagus) or the conifers such as spruce (Picea) and pine (Pinus). Consequently, there is great concern about the impacts that $B$. pendula and overall vegetation may be having on the bog hydrology. The purpose of this study was to examine the relationship of B. pendula and the water table level at Wainfleet Bog.

\section{Study Area}

Wainfleet Bog is the largest Class 1 provincially significant wetland in the Niagara Region, the highest rating according to the classification scheme set out by the Ontario Ministry of Natural Resources 1992. It is located near the towns of Port Colborne and Welland in southern Ontario. The bog is 1500 ha in size with peripheral areas of fen, marsh and swamp forest. It has an elevation between $175.5 \mathrm{~m}$ and $178.5 \mathrm{~m}$ on the Haldimand Clay Plain at latitude of $42^{\circ} 55^{\prime} \mathrm{N}$ and longitude of $79^{\circ} 17^{\prime} \mathrm{W}$. The bog has an east-west length of approximately $5 \mathrm{~km}$ and a north-south expanse of approximately $3.5 \mathrm{~km}$. Adjacent land uses around the perimeter include agriculture, quarrying, an industrial park and a major highway. Wainfleet Bog is relatively young and shallow with a maximum peat depth of $5 \mathrm{~m}$, and approximate average peat depth of $3 \mathrm{~m}$. Core and tests of the lowermost organic stratum suggest that the age of Wainfleet Bog is approximately 5000 years B.P. (Jonsson-Ninniss and Middleton 1991).

Over the last century, Wainfleet Bog has been extensively mined for peat moss using block cutting methods initially, and later vacuum harvesting. The central area of the bog is the most disturbed. Extraction of peat resulted in serious ecological impacts within the bog. The most disturbed areas were completely stripped of vegetation to expose the peat. Exposed peat was allowed to dry, and was then harvested using vacuum machinery. The bog's hydrology has also been severely altered through the construction of drainage ditches to facilitate the peat harvesting process. The only relatively undisturbed area within Wainfleet Bog has been designated an Area of Natural and Scientific Interest
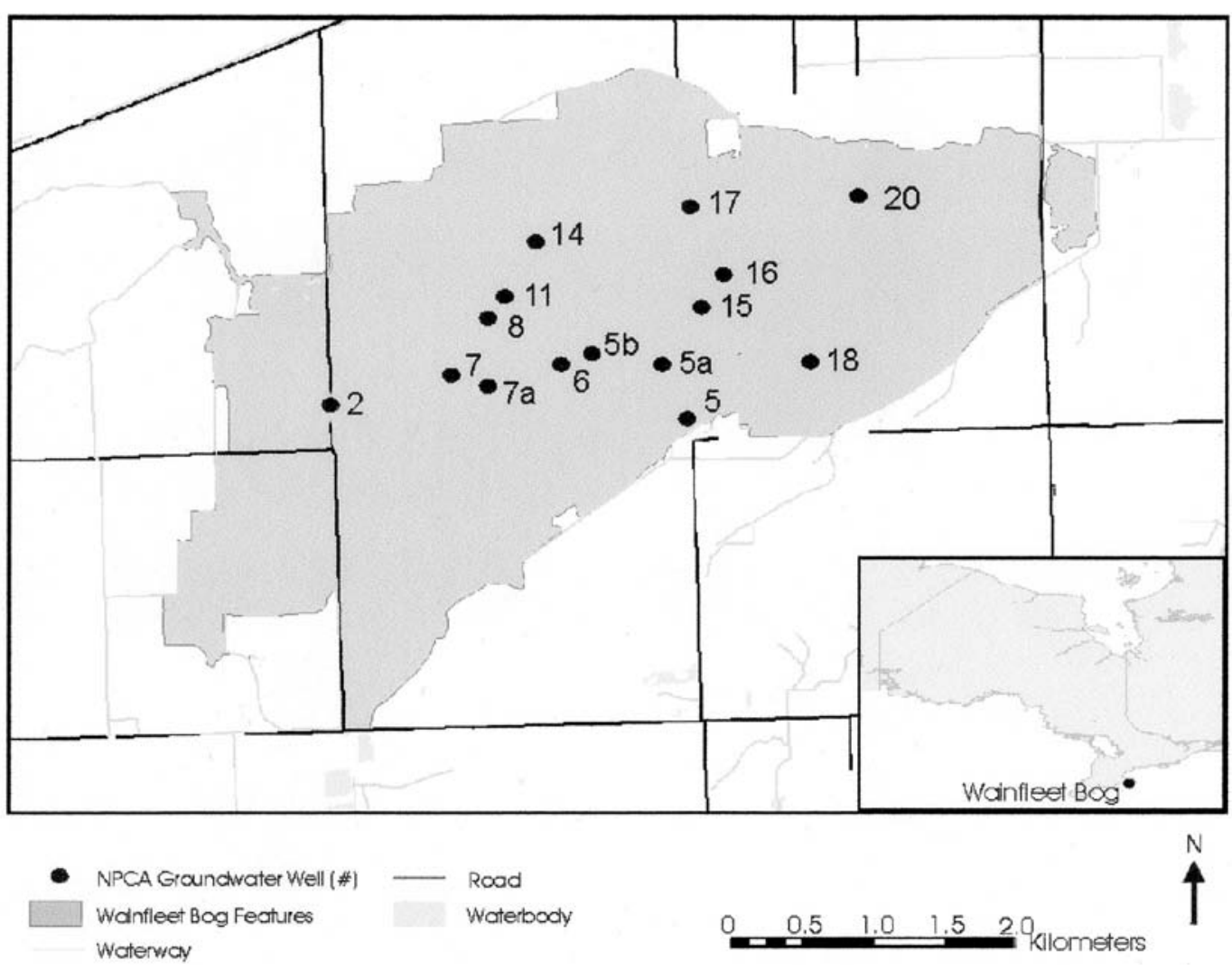
TABLE 1. Summary of the repeated measures Analysis of Variance for the presence of Betula pendula and other woody vegetation at Wainfleet $\mathrm{Bog}(\mathrm{P}>0.05)$.

\begin{tabular}{|c|c|c|c|c|c|}
\hline Source & Type III Sum of Error & df & Mean Square & $\mathrm{F}$ & P-value \\
\hline B. pendula present & 2.285 & 1 & 2.285 & 1.886 & 0.195 \\
\hline Non-B. pendula woody vegetation present & 1.363 & 1 & 1.363 & 1.125 & 0.31 \\
\hline Error & 14.542 & 12 & 1.212 & & \\
\hline
\end{tabular}

(ANSI). The ANSI is 200 ha in size and has not been subjected to direct peat harvesting or its related impacts. However, peat harvesting and drainage in the other sections of the bog have allowed for both a depression in the water table and the invasion of $B$. pendula in the ANSI.

Trembling Aspen (Populus tremuloides), birch (Betula spp.) and Black Cherry (Prunus serotina) form a forest belt between the interior of the bog and the surrounding farm land (Jonnson-Ninniss and Middleton 1991). Disturbed areas of the bog may be free of living vegetation, dominated by the tall ericacious shrubs Aronia melanocarpa and Vaccinium corymbosum, or have a closed canopy of primarily $B$. pendula. In the most recent, vacuum-mined sites often only three species are present: hair-cap moss (Polytrichum strictum), bunch cotton-grass (Eriophorum vaginatum) and $B$. pendula. The least disturbed areas are open with a few scattered trees; ground cover is predominately Sphagnum mosses and ericacious shrubs.

\section{Methods}

To monitor water level fluctuations at Wainfleet Bog, the Niagara Peninsula Conservation Authority (NPCA) set up 25 well stations. These wells were made of $5 \mathrm{~cm}$ diameter PVC pipe and were distributed throughout the bog. Water level data have been collected by the NPCA on a near-monthly basis from March 1998 to the present. For this study, well station data were used from 31 March 1998, 4 June 1998, 17 June 1998, 2 July 1998, 16 July 1998, 30 July 1998, 27 August 1998, 24 March 1999, 15 April 1999, 19 May 1999, 2 June 1999, and 16 June 1999. On several occasions the water level at various well stations was too low to be detected and resulted in no water level reading for that particular observation. Subsequently observations of this nature were removed from the data set.

Vegetative data were collected at 15 existing well stations distributed throughout the bog (Figure 1). At each well station a compass bearing of northeast was taken. From each well station, following the northeast bearing, $11.28 \mathrm{~m}$ was measured out to point A. Point A became the centre of a circular plot of $11.28 \mathrm{~m}$ radius (1/25 ha). Around point A starting at due north (0 degrees) and moving east, all trees were numbered consecutively with tree paint. Any living trees with a diameter at breast height (dbh) of $9.5 \mathrm{~cm}$ dbh and within the $1 / 25$ ha circular plot were counted. Trees forked at or below breast height counted as two trees. The dbh of all trees greater than $9.5 \mathrm{~cm}$ was recorded. All trees surveyed in this circle plot were identified to species.

In addition to the circle plot, a $10 \mathrm{~m}$ by $10 \mathrm{~m}$ square plot was set up for each well station. Point A was used as the centre of this plot. Orientation of this plot was set to due north. This $10 \mathrm{~m}$ by $10 \mathrm{~m}$ plot was divided to form ten $1 \mathrm{~m}$ by $10 \mathrm{~m}$ plots. One of these $1 \mathrm{~m}$ by $10 \mathrm{~m}$ plots was selected randomly, and all saplings or shrub stems less than $9.5 \mathrm{~cm}$ dbh and greater than $1 \mathrm{~m}$ in height were counted and identified. No dbh data were taken for these smaller trees.

The data in this study were analyzed with a Repeated Measures Design (Johnson and Wichern 1992). The assumptions for this statistical procedure were tested utilizing the Kolmogorov-Smirnov Test of Normality, and Levene's Test of Equality of Error Variance. Each of these assumptions was met. Well stations were assumed to be independent when the distance between each well station was greater than 10 metres, based on hydrological studies of the bog (NCPA: Wainfleet Bog Hydrological Assessment Meeting, unpublished data). All stations used in this study were separated by a minimum of $10 \mathrm{~m}$.

Invasion by woody vegetation, and specifically Betula spp. in abandoned peatlands, has been reported as having the potential to have detrimental effects on the water table (Lavoie and Saint-Louis 1999). The statistical design developed for this analysis tested the null hypothesis that vegetation (particularly B. pendula) and water table level are independent. A summary of the statistical design is found below. The biological predications of this study were that plots with a high population of $B$. pendula would have a lower water table level due to the effects of evapotranspiration, while plots with a low population of $B$. pendula would have higher water table levels.

Statistical Design

Water Level $=$ Intercept $($ Mean Water Level $)+$ Effect Due to Presence of B. pendula* + Effect Due to Presence of Other Woody Vegetation $\bullet$

* Represents an effect due only to the presence of B. pendula

- Represents an effect due to the presence of all other woody vegetation not including $B$. pendula 


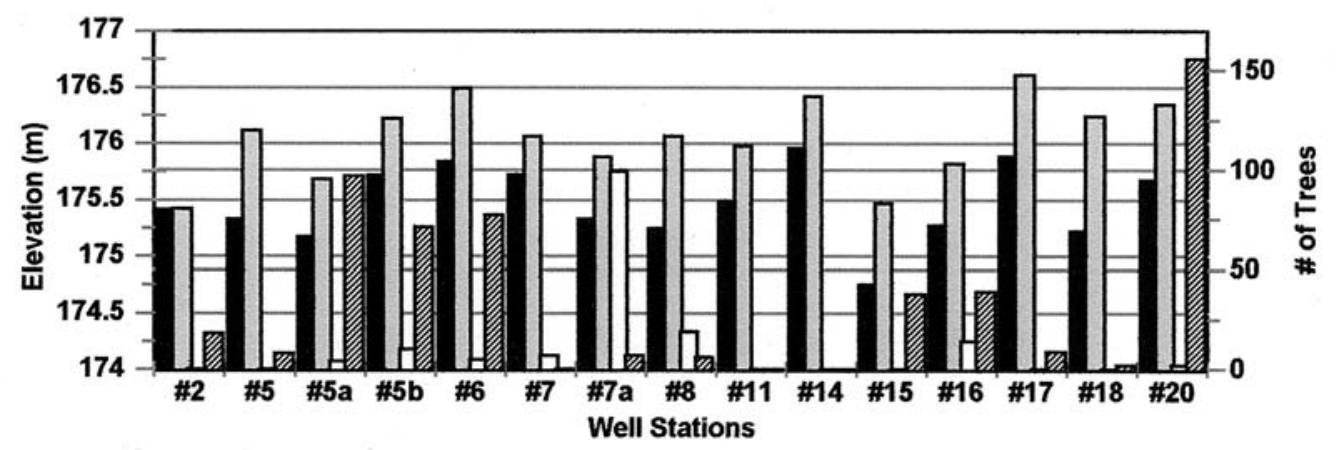

Water Level

Surface Elevation

$\square$ \# of B. pendula

\# Non-B.pendula

FIGURE 2. Surface elevation, mean water (31 March 1998 -16 June 1999), and the number of $B$. pendula and non- $B$. pendula found at each well station.
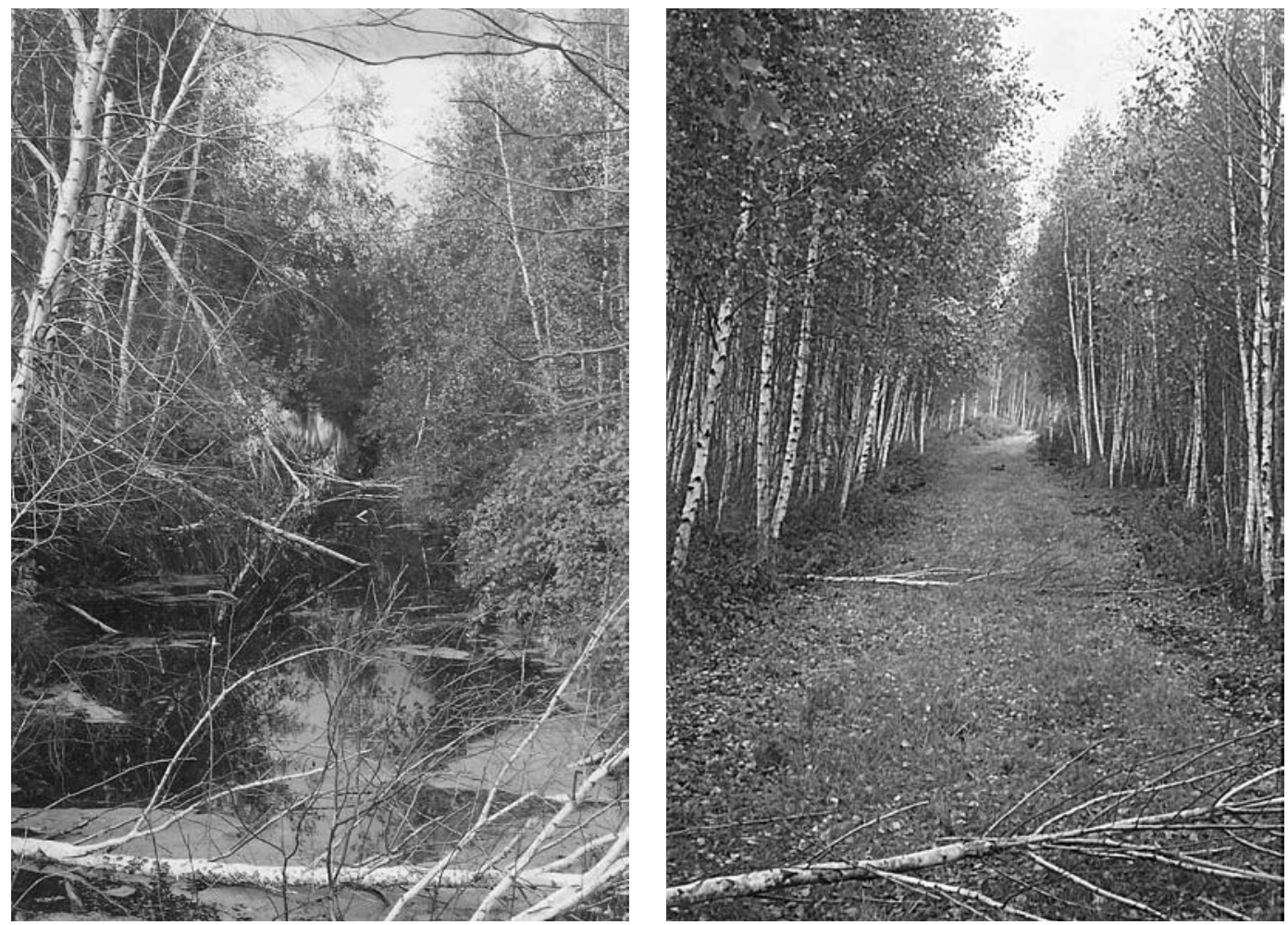

FIGURE 3. Betula pendula in the regenerating areas of Wainfleet Bog.

still exist in Wainfleet Bog. It is possible that restoration of the bog hydrology can be obtained by filling and dismantling these drainage ditches. However, this strategy is being initiated gradually as organisms such as the Massasauga Rattlesnake may have become dependent upon the altered drier conditions of the bog. It is also not entirely clear whether higher water table levels would provide a control solution as $B$. pendula 


\section{Results and Discussion}

The results of the Repeated Measures Design failed to demonstrate a significant relationship between $B$. pendula (ANOVA, $\mathrm{P}>0.05$ ) or non- $B$. pendula vegetation (ANOVA, $\mathrm{P}>0.05$ ) and water table level (Table 1). A summary of the data can be found in Table 2. According to Schouwenaars (1993), the groundwater in bog ecosystems reaches the surface during most of the winter period, and this water should not be deeper than $30-40 \mathrm{~cm}$ in the summer. In Figure 2, several well stations $(5,8,18)$ had no $B$. pendula and minimal non$B$. pendula vegetation, yet water table levels remain lower than the range of levels suggested by Schouwenaars in a healthy bog ecosystem. In comparison, station 2 has a water table level within the range suggested by Schouwenaars, yet there are a substantial number of trees present at this site, although only two are $B$. pendula. These findings would suggest that $B$. pendula and non-birch woody vegetation are not the primary factors affecting the water table level of Wainfleet Bog. However, the cause of the variation in birch tree density in the bog remains obscure and probably involves factors other than the obvious ones of water table level and length of regeneration.

Cross (1987) observed an unusual stand of birch trees growing successfully on a moderately disturbed bog in Ireland (All Saints Bog). It is 230 ha in size, and has a plant community typical of a raised bog ecosystem. The water table of this bog is at the surface, and the peat has a $\mathrm{pH}$ of 4.0 . Within this bog, a welldeveloped 20 ha birch community made up of $B$. pendula and B. pubescens exists. Cross observed no significant effects of the birches on the water table in this community. However, Schouwnaars (1988) does indicate evapotranspiration should not be ruled out of any hydrological modelling when considering bog restoration.

The most damaging attribute of $B$. pendula is the occupation of habitats that regenerating bog vegetation would normally occupy. The scale of the birch tree infestation in the regenerating areas of the bog is large, with trees extending thickly over several hundred hectares (Figure 3). This invasion of B. pendula has led to the destruction of open bog vegetation as non-acidic deciduous leaf litter often buries the bog plants (MacDonald 1992). The decomposition of such leaf litter is contributing excessive nutrients to the bog which, under undisturbed conditions, would be nutrient deficient. In addition, the birch forest canopy is intercepting light that would normally reach the bog vegetation and this should also be considered a substantial impact (MacDonald 1992). Further studies of $B$. pendula that quantify its exact mechanism of impact are necessary if restoration of the Sphagnum layer is to be attempted.

Recent findings by the NPCA (unpublished data) suggest that the hydrology is most affected by the series of interior and exterior drainage ditches which

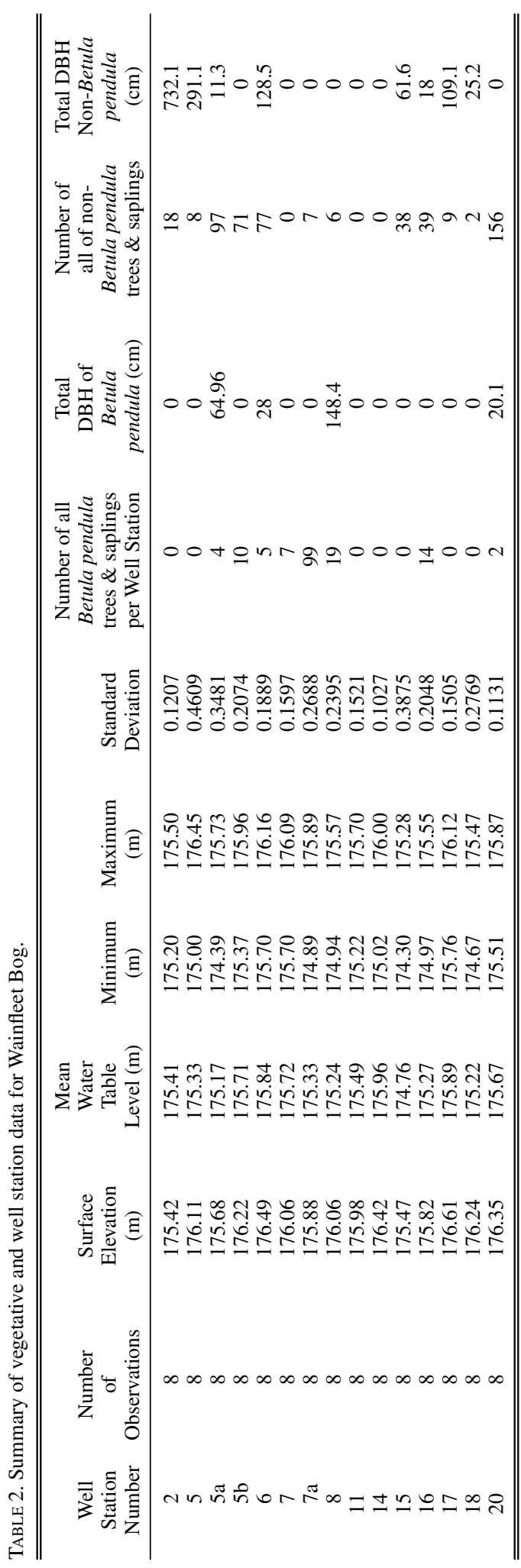


has been found to inhabit undisturbed bog conditions (Cross 1987). Other strategies for controlling B. pendula in the bog, as well as other hydrology studies, are currently under way (NPCA, unpublished data).

We conclude that the results of this study failed to demonstrate a significant relationship between the presence of $B$. pendula or other woody vegetation with water table level in Wainfleet Bog. The population of $B$. pendula at Wainfleet Bog is alarming for many ecological reasons, but its direct impact on hydrology remains to be demonstrated.

\section{Acknowledgments}

We thank Kim Frohlich and Geoff Verkade of the Niagara Peninsula Conservation Authority for providing us with water well data and various other resources. We are also very grateful for the assistance of Karen Krug of Brock University for her comments on the earlier parts of this study.

\section{Literature Cited}

Atkinson, M. D. 1992. Betula pendula Roth (B. verruscosa Ehrh.) and B. pubescens Ehrh. Journal of Ecology 80: 837870 .

Catling, P. M., and K. W. Spicer. 1988. The separation of Betula populifolia and Betula pendula and their status in Ontario. Canadian Journal of Forest Research 18: 10171026.

Clymos, R. S., and P. M. Hayward. 1982. The Ecology of Sphagnum. Pages 229-289 in Bryophyte Ecology. Chapman and Hall, New York.

Cross, J. A. 1987. Unusual stands of birch on bogs. Irish Naturalist Journal 22: 305-310.

Environment Canada. 1986. Canada's wetlands: National Wetland Group. Canada Committee on Ecological Land Classification, Environment Canada, Ottawa.

Environment Canada. 1997. Conserving vitality and diversity: proceedings of World Conservation Congress, workshop on alien species. Environment Canada, Ottawa.
Houle, G. 1991. Regeneration traits of tree species in deciduous forest of northern North America. Holarctic Ecology 14: 142-151.

Johnson, R. A., and D. W. Wichern. 1992. Applied multivariate statistical analysis. Prentice Hall, New Jersey.

Jonsson-Ninniss, S., and J. Middleton. 1991. Effect of peat extraction on the vegetation in Wainfleet Bog, Ontario. Canadian Field-Naturalist 105: 505-511.

Kozlowski, T. T., and S. G. Pallardy. 1997. Physiology of woody plants. Second edition. Academic Press, San Diego.

Lavoie, C., and A. Saint-Louis. 1999. The spread of gray birch (Betula populifolia) in eastern Quebec: landscape and historical considerations. Canadian Journal of Botany 77: 859-868.

MacDonald, I. D. 1992. A biological inventory and evaluation of the Wainfleet Bog Area of Natural and Scientific Interest. Ministry of Natural Resources, Ontario.

Niagara Peninsula Conservation Authority. 1997. Wainfleet Bog management plan, Wainfleet Ontario. Niagara Peninsula Conservation Authority, Welland, Ontario.

Ontario Ministry of Natural Resources and Ministry of Rural Affairs. 1992. Manual of implementation guidelines for the Wetlands Policy Statement. Toronto, Ontario.

Reyes, O., M. Casal, and L. Trabaud. 1997. The influence of population, fire and time of dissemination on the germination of Betula pendula seeds. Plant Ecology 133: 201-208.

Salonen, V. 1987. Relationship between the seed rain and the establishment of vegetation in two areas abandoned after peat harvesting. Holarctic Ecology 10: 171-174.

Schouwenaars, J. M. 1988. The impact of water management upon groundwater fluctuations in a disturbed bog relict. Agricultural Water Management 14: 439-449.

Schouwenaars, J. M. 1993. Hydrological differences between bogs and bog-relicts and consequences for bog restoration. Hydrobiologia 265: 217-224.

Wind-Mulder, H. L., L. Rochefort, and D. H. Vitt. 1996. Water and peat chemistry comparisons of natural and postharvested peatlands across Canada and their relevance to peatland restoration. Ecological Engineering 7: 161-181.

Received 6 July 2001

Accepted 17 March 2004 